\title{
Pharyngeal Fistula
}

National Cancer Institute

\section{Source}

National Cancer Institute. Pharyngeal Fistula. NCI Thesaurus. Code C78551.

An abnormal communication between the pharynx and another org an or anatomic site. 